\title{
Network Organizations: Symmetric Cooperation or Multivalent Negotiation?
}

\author{
Hamid R. Ekbia \\ Computer Science Department, University of Redlands, Redlands, California, USA \\ Rob Kling \\ School of Library and Information Science, Indiana University, Bloomington, Indiana, USA
}

The network model of organization plays a central role in recent sociological accounts of the information economy. This model is also often presented in organization and information and communication technologies (ICT) literature with an air of enthusiasm that underscores its advantages-flexibility, cooperative culture, innovativeness, and knowledge and technology intensity. Such themes are usually based on a "networking logic" that assumes the trustful cooperation of large and small production firms in a rapidly changing economic environment. We believe that both the logic and the themes based upon it are too narrow to be able to explain the complex dimensions of interorganizational networking. Using Enron as a case study, our goal in this article is to enrich the logic just described and to develop an extended model of the network enterprise. We argue that this is only possible by extending the unit of analysis beyond the production firm, to include, among others, subsidiaries, banks, investors, auditors, and government agencies. The proposed extended model allows the broadening of many of the aforementioned themes, making it possible to arrive at a realistic picture of the complexities of the network enterprise. The managerial advantages of the model are also discussed.

Sociological accounts of the information society are increasingly focused on the networked character of present day societies. Castells (1996, 2000, 2001), for instance, features the network enterprise as the human engine and the centerpiece of an informational economy. The picture presented is one of a multiply nested organization in which divisions of large multinational corporations cooperate on a project-by-project basis with small and medium firms leveraging the advantages of the new information and communication technologies (ICT) (Kraak, 2000). The flexibility and market orientation of the network organization are foregrounded by this characterization. Furthermore, Castells's notion of the network enterprise amplifies the global and international scope of his analysis, as opposed to, for instance, Bell's (1973) national perspective. It provides the big picture - that is, network organization as part of a grand narrative that, in the absence of other comprehensive accounts, is much needed, and for which Castells has deservedly received much acclaim (Staider, 1998; Eades, 2000; Crabtree, 2002; Kling, in press) and a tinge of harsh criticism (Abell \& Reyniers, 2000).

Castells' account articulates the major background assumptions in many other studies of the network form - for instance, many theoretical studies in the organization and business literature (Powell, 1990; Miles et al., 1992; Miles \& Snow, 1995; Nohria \& Eccles, 1992; Grandori \& Soda, 1995; Polodny \& Page, 1998; Symon 2000), information and communication systems literature (Ching et al., 1996; Van Alstyne, 1997; Fulk \& Desanctis, 1998), and studies that focus on the practical aspects of the network form (e.g., Bovasso, 1992; Hanssen-Bauer \& Snow, 1996; Fulkerson, 2000; Camuffo et al., 2001; Ragatz et al., 2002). These studies emanate from different perspectives but they converge on a number of 
themes-most importantly, interfirm cooperation, trust, voluntarism, intrafirm teamwork, empowerment, innovation, organizational flexibility, adaptability, decentralization, and, most often, ICTenabled processes (Van Alstyne, 1997).

One common thread runs through the accounts just described and that of Castells's notion of "networking logic." Castells asserts that this logic "seems to be well adapted to increasing complexity of interaction and to unpredictable patterns of development arising from the creative power of such interaction" (Castells, 1996, p. 70). Although the precise character of these interactions is far from clear in Castells's account, they rely heavily on ICT-enabled processes (pp. 61-62). Some organizational theorists also use the notion of an "operating logic" to explain the limits and capabilities of different organizational forms-hierarchy, division, matrix, and, more recently, the network organization (e.g., Miles \& Snow, 1992). As we show, despite their dissimilar origins, these two logics converge on a similar set of assumptions and themes, especially the primacy of univalent, trustful, cooperative links among all the components of a network enterprise.

A close look at some real-world cases would reveal that the purported logics and assumptions are too narrow to accommodate the full complexity of networking practices in the current economy. One such (in)famous case is that of Enron, which, as we show, represents a faithful implementation of the network form as characterized by Castells and others. For many years, Enron was the subject of admiration in business and management literature (Sherman, 2002), until December 2001, when a business scandal brought down the corporation in the largest bankruptcy case in American business history till then. Yet nobody foresaw Enron's downfall, and the question is why. A good part of the answer, we argue, lies in the simplicity of these logics and the assumptions on which they are based. While they have provided useful insights into the potential and advantages of the network form over previous forms of organization, they also bring with them conceptual blinders that overlook the dark side of network organizations. The Enron case begs for a much broader view of the network organization.

Our goal in this article is to develop a realistic theory of the network enterprise that can explain both the strengths and weaknesses of this form of organization.We start with the assumption that, in the most general case, the links among network components might be multivalent and nuanced, ranging in character from complete trust, voluntarism, and cooperation to outright deception, coercion, and antagonism. This leads to a multivalent negotiated network (MNN) model that includes as a special case the univalent cooperative network (UCN) model presented in Castells and the organization literature in general. Our purpose is not to discard UCN models, but to develop a framework that includes the web of “complex, negotiated, and multivalent” links and relationships that constitute such networks (Kling \& Lamb, 2000). This broad framework makes it possible to see the tensions that can develop in a network organization as it happened in the case of Enron.

The article continues in the second section with a review of prior theories of network organizations, and in the third section with a brief history of Enron, with a focus on its network structure. The fourth section presents our methods, the fifth section outlines our theory and illustrates it in the context of Enron, and the sixth section generalizes the MNN model in its most basic outline. The article concludes with some general lessons.

\section{PRIOR THEORY}

There are numerous accounts of the network enterprise emanating from various perspectives. Among them, Castells's account stands out as a grand narrative of a new mode of production, which is based on 
the network form of social organization and is empowered by new ICT. This narrative, as we suggested, elucidates the background assumptions and the logic behind most other accounts of network organization, so we begin our examination of current accounts with Castells's theory.

\section{The Network Society and Its Networking Logic}

According to Castells, we live in a new economy, characterized by three fundamental features (2000, p. 10):

1. Informational: The capacity of generating knowledge and processing/managing information determine the productivity and competitiveness of firms.

2. Global: Its core, strategic activities (finance, R\&D, trade, services, etc.) have the capacity to work as a unit on a global scale.

3. Networked: It is based on a new form of economic organization, the network enterprise.

What is particularly new about this economy, according to Castells, is the emergence of newICT, especially the recent shift from computer-centered to network-diffused technologies. This gives rise to a "virtuous circle," where the use of knowledge-based, information technologies leads to an increasing generation of knowledge that, in turn, calls for further employment of those technologies. According to Castells, these technologies have also brought about serious transformations in the nature of work, such as flexible schedules, a culture organized around electronic media, politics that is media-centered and very expensive (hence, corruptible), and a nation-state whose legitimacy is undermined, turning it into the "network state" that shares power with other local, national, and international institutions. Most prominent among these various transformations, however, is the emergence of the network enterprise, characterized by Castells as "information networks, which, in the limit, link up suppliers and customers through one firm, with this firm being essentially an intermediary of supply and demand, collecting a fee for its ability to process information" (2000, pp. 10- 11). Castells bequeaths to this network "an unprecedented combination of flexibility and task implementation, of coordinated decision making, and decentralized execution” $(2000,15)$.

TABLE 1

Common Background Assumptions in Castells's

Account of Network Organizations

1. Market orientation in economic activity

2. Trust as the dominant relational modality

3. Flexibility in response to market demands

4. Adaptability in dealing with changing environment

5. Informationlism in terms of mode of production

6. Deregulation in relation to governments

7. Internationalism in scale

In short, Castells's account is based on a number of premises that, as we mentioned, constitute the background assumptions in most other accounts of the network organization (see Table 1). 


\section{Univalent Cooperative Networks}

The network form of organization has been the topic of much discussion and theorizing among organization theorists. Although there are significant differences in the positions of different theorists, the core assumptions converge on a set of common features. Baker (1992) describes the network organization as one that "can flexibly construct a unique set of internal and external linkages for each unique project" (398). Miles and Snow (1995) portray the "voluntary, cooperative network" as one that is "delayered, highly flexible, and controlled by market mechanisms rather than administrative procedures” (p. 5). Van Alstyne (1997), comparing and contrasting the computational, economic, and societal metaphors of network organizations, finds "collective purpose" as a distinguishing design element of networks from centralized organization, and emphasizes the role of "reputations, commitments, and trust" in their functioning. The notion of an "organic form of organization," developed by Burns and Stalker (1961), has also been invoked to foreground the cooperative character of network organizations (Bovasso, 1992). In short, as Fulk (2001, p. 91) has summed up, a burst of theory and analysis has established "the network as the most important emergent organizational structure and the pre-eminent metaphor for sense making by academics and practitioners alike.”

TABLE 2

Common Themes Among Accounts of Network Organizations

1. Cooperation in interfirm connections

2. Voluntarism as the dominant interfirm relationship

3. Team spirit in intrafirm relations

4. Decentralization in organizational structure

5. Empowerment in management style

6. Transparency of operational mechanisms

Terminological differences notwithstanding, the unequivocal focus among these views is the often cooperative character of network organizations (cf. Grandori \& Soda, 1995, for a review). We therefore call the models built upon such views univalent cooperative networks (UCN). The focus in UCN models on the production firm leads to an emphasis on cooperation and streamlining in both intra- and interorganizational relations of network enterprises. This picture is based on a number of major themes listed in Table 2.

Some sociologists have emphasized the efficiency and effectiveness of alliance capitalism in comparison to a capitalism premised on arms-length transactions among large hierarchies. As Polodny and Page $(1998,71)$ argue, however, "this enthusiasm for network forms of organization seems difficult to reconcile with an important fact: An extremely large fraction of network forms of organization do not perform the function for which they were designed." To accommodate this fact, we want to develop an alternative theory of the network organization, and Enron provides a useful example for this purpose

\section{ENRON: THE PARADIGMATIC NETWORK ORGANIZATION}


Founded in 1984 with the merger of Houston Natural Gas and Internorth (which carried out the exploration, production, and transfer of oil and gas), Enron Corporation morphed into one of the largest U.S. corporations - $\$ 100$ billion in revenue, $\$ 60$ billion market value, and 20,000 employees around the globe circa 2001.The central vision behind Enron's enterprise was to fully use the financial and derivatives markets: to buy a commodity that somebody wanted to sell, and then sell it for a profit to someone who wanted to buy it. Often Enron sought to sell capacity; it began with oil and natural gas, and expanded to pulp, paper, lumber, coal, steel, and water (Rubenstein, 2001). In 2001 Enron Wholesale Services (EWS) traded over 1000 kinds of products (Rubenstein, 2001), and had added 1700 (derivate) products in 20 markets (Maselli, 2001). It was this approach to the derivatives market that allowed Enron to diversify its activities over a broad range of products and services, and to branch out its organization in different directions. Enron had created more than 870 off-balance-sheet subsidiaries as legal and organizational vehicles for carrying out these activities (Swartz \& Watkins, 2003).

For these and other reasons, a visible consensus of Enron executives, financial analysts, information technology (IT) specialists, and business media portrayed in their recurring stories a very flamboyant picture of Enron. This enthusiasm started to fall off around October 2001, and came to a halt with the collapse of Enron on December 2, 2001. Careful scrutiny reveals a close association between the running themes of these enthusiastic stories and the basic assumptions of theoretical accounts of the network enterprise- - broad networking strategy, cooperation with partners, market orientation, extensive use of ICT, and so on. The enthusiasm surrounding Enron kept many observers from noticing its flaws and failures, or ignoring them if noticed. In reality, however, Enron had its share of failed business projects from early on, especially on the international scene. The most controversial project was LJM2 Co-Investment LP. Although critics consider entities such as these little more than shells, LJM2 was more than a paper company (Bilodeau, 2002). Formed in 1999, LJM2 was regarded as an "alternative, optional source of private equity for Enron to manage its investment portfolio risk, funds flow, and financial flexibility” (Bilodeau, 2002). Its limited partners included a wide spectrum of individuals and institutions-from financial entities such as Merrill Lynch \& Co., J. P. Morgan Partners, American International Group, Inc., and Leon Levy, the former chairman of Oppenheimer Funds, Inc., to the Arkansas Teacher Retirement System, Princeton University's Institute for Advanced Study (of which Levy is vice-chairman), and John Friedenrich, a former chairman of the board of Stanford University. The investments of these investors ranged anywhere from $\$ 500,000$ to $\$ 30$ million, and they were probably lured into the partnership by different motivations and expectations, but their diversity speaks to the complexity of the networks that were woven inside and outside of Enron.

Enron epitomizes a network form of organization on different organizational, operational, financial, and technological dimensions. Organizationally, Enron was divided into many different parts and activities-Enron Wholesale Services (EWS), Enron Energy Services (EES), Enron Transportation Services (ETS), Enron Broadband Services (EBS), and so on. On the outside, Enron had links with a huge number of organizations, which consisted of subsidiaries-Enron Communications (ENE), Azurix Corp. (water unit), etc.-as well as partnerships and alliances-LJM1/2, JEDI partnership with Calpers (California State Employees’ Pension Fund), Raptors (a partnership with Ciena Corp. and Cisco Systems to implement Enron Intelligent Network), partnerships with Global Crossing and Qwest for trading bandwidth, and so on. Enron was surrounded by a huge network of special purpose entities (SPE), many of which were accounting or legal artifacts with unique and innovative relationships with the company. Figure 1 demonstrates part of the complexity of these networks. 
Technologically, Enron was among the most heavily wired companies of the 1990s. Many years after its ascendance, the up-to-date quality of Enron technology was still a point of envy for firms all over the world. Its operations extended throughout the Americas, Europe, Africa, and many parts of Asia (Share, 1999). It is reported that $60 \%$ of Enron trades were done over the Internet by Enron Online (EOL), which was able to provide real-time prices for as many as 30 trades per minute, increasing the average number of trades for each trader to five per day instead of the traditional three per week (Maselli, 2001).

Financially, a large group of major and minor banks and investment firms was linked to Enron in various ways. The multiplicity and variety of these links provides a complex picture of the financial networks surrounding the company. Very briefly, while the security firms (J. P. Morgan Chase, Merrill Lynch, Citigroup, and others) were trading Enron's stocks through their brokerage divisions, their analysts were involved in evaluating the company's performance, and their managers, sometimes having personally invested in Enron, provided consultation advice to its executives. These multiple, often conflicting, links generated a complex web of inconsistent relationships, the implications of which have become the subject of much legal inquiry and criminal investigation (Chaffin, 2002; Creswell, 2002; Greider, 2002; Oppel, 2002; Wayne, 2002). What was often portrayed as a lender-borrower relationship was, indeed, a multivalent relationship that, on the one hand, forced Enron to meet Wall Street expectations and, on the other, turned the banks into promotional agents and propaganda mouthpieces of Enron.

To make this picture even more complicated, there were major differences in the relationships of Enron with different classes of investors and creditors. While big creditors had at least partial access to insider information, minor creditors did not enjoy that privileged status. These relationships followed different developmental paths over the years. Big creditors, having become heavily involved with Enron's finances (mainly through inflated interest rates), had much at stake to maintain the status quo by promoting Enron's reputation. Thus, when the situation started to deteriorate, the big creditors basically collaborated in false image making with Enron. "If they stopped pedaling," to use the apt analogy suggested in Greider (2002, p. 5), "the bicycle would fall over." One aspect of this accelerating dynamicswas an increasingly tighter relationship between the banks and Enron, a point of significance in later accusations of insider trading by banks. Minor investors' relationship with Enron, on the other hand, followed an almost opposite tack. Although they were likewise lured into cooperative investment by the promise of grand profits, their links with Enron gradually degenerated into deception and victimization, as manifested in the pursuing legal investigations. 


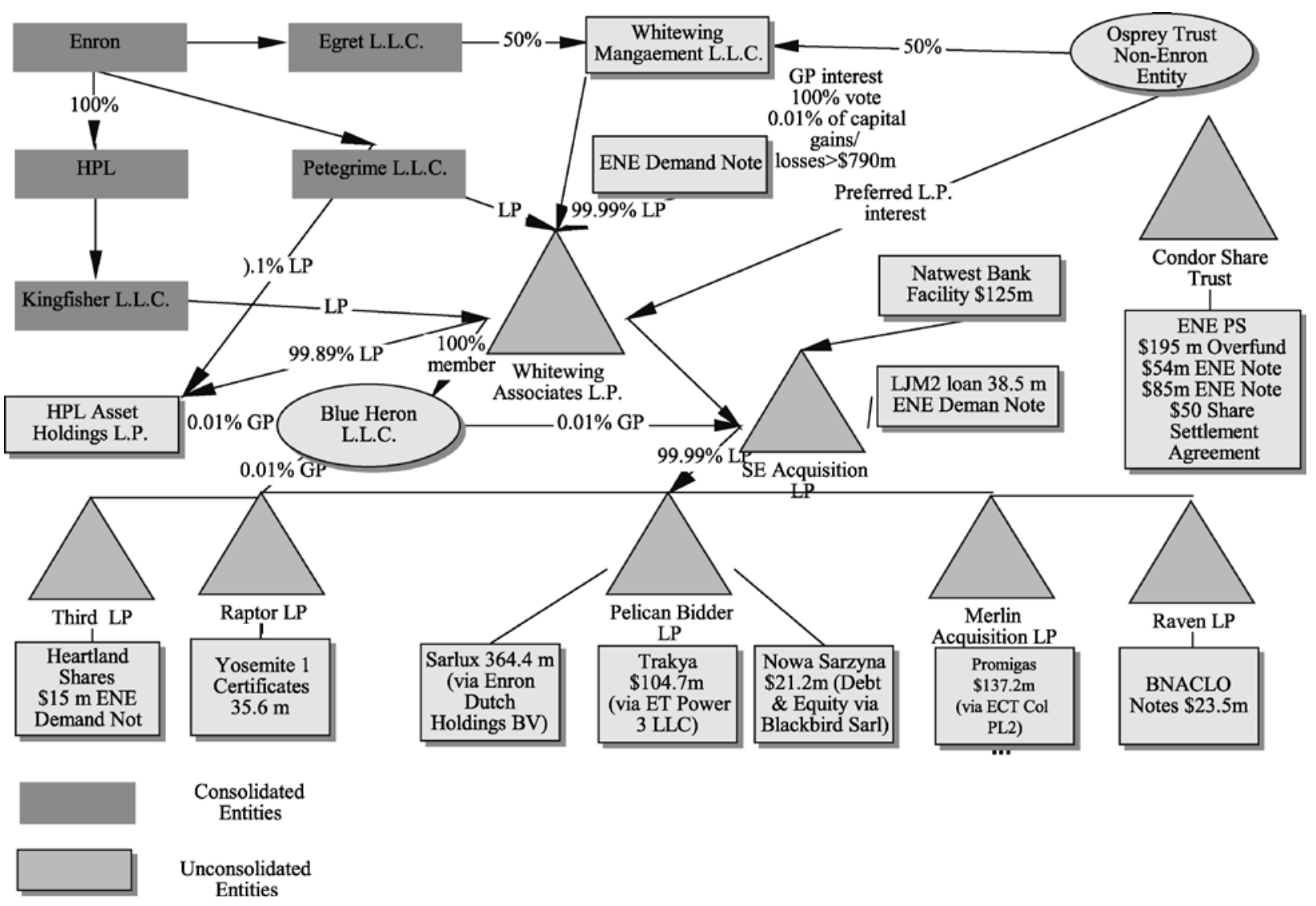

FIG. 1. Example of Enron’s complex SPE structures. (Redrawn from Swartz and Watkins (2003).

In sum, Enron can be justifiably deemed as a paradigmatic example of a network organization on many levels. In fact, a comparison with Cisco, which Castells (2001) features as the prime example of a successful network enterprise, would show that Enron is no less exemplary than Cisco of a network organization (see Table 3).

TABLE 3

A Comparison Between Cisco Systems and Enron as Network Organizations

\begin{tabular}{lll} 
Case criterion & Enron & Cisco \\
\hline Internet trade & $60 \%$ & $90 \%$ \\
Online sales (millions/day) & $\$ 10,000$ & $\$ 40$ \\
& $(1999)$ & (first half 2000) \\
Number of partnerships & $\sim 1800$ & 70 \\
\hline
\end{tabular}

\section{METHODOLOGY}


The current study fits the general category of "building theory from case study research" (Eisenhardt, 1989). In his study of the "spaghetti organization" of hearing-aid manufacturer Oticon, for instance, Foss (2001, 2) has applied this method, relying "on archival sources, newspaper and magazine articles, and, in particular, the large number of very rich and thick descriptions of Oticon.” We have followed a similar research strategy. Our goal is to develop theory, and the choice of Enron is motivated by the observation that there is not much research on network failures, despite the fact that there are numerous cases of such failures (Polodny \& Page, 1998). This study, as such, contributes to and complements the current literature.

Enron has been under the spotlight for many years, originally for its highly rated performance throughout the 1990s and then for its controversial collapse in December 2001. This public exposure generated an abundance of data, in both professional journals and the popular press, which was very useful for our current study. In using these data, we seek to understand neither the causes of the failure of Enron nor the character of corporate crime. In our view, success and failure, as binary attributes, are not useful analytic concepts, and we are careful not to make inferences solely on the basis of "success" or "failure" as they are commonly judged in popular business writings. Instead, we seek to enhance our understanding of the interactions of an organization with its externalities and the dynamics of networking in the current economy.

Toward this end, we propose a shift in terms of the unit of analysis. As Polodny and Page have shown, current accounts of network organization are biased in their treatment of success and failure of network enterprises at the risk of a naive functionalism $(1998,73)$. One indication of this kind of functionalism is the exclusive focus on the production firm. Miles, Snow, and Coleman (1992), for instance, discuss three different types of network organization - internal, stable, and dynamic networksthe common feature of which is the centrality of the production firm. Castells $(1996,214)$, on the other hand, characterizes the network enterprise as "an intermediary of supply and demand," but takes the "project" as the unit of analysis, despite his emphasis on the network as "the unit of economic organization." We believe that neither of these, the production firm or the project, provides the right unit of analysis for understanding network organizations. Following Powell (2000), we would like to suggest as the appropriate unit of analysis the extended network that includes, among others, the partnerships, banks, brokerage firms, auditors, and government agencies. We strongly concur with Powell that "the boundaries of many firms have become so porous that to focus on boundaries means only to see trees in a forest of interorganizational relations," and that "fixing the boundaries of an organization becomes a nearly impossible task"-hence, the mandate of taking "the interorganizational network as the basic unit of analysis” (Powell, 2000).

In short, in contrast to prior theories, we want to expand the unit of analysis, revise the logic, and broaden the assumptions in order to be able to grasp all the aspects of a case such as Enron.

\section{A NEW THEORY: MULTIVALENT NEGOTIATED NETWORKS}

From what we learned about Enron, it would seem that the themes outlined in Table 2, while useful organizing themes in the discussion of the network enterprise, are certainly not the only conceivable ones. Similarly, the background assumptions outlined in Table 1 hold up in some cases but not in others. In fact, as the case of Enron illustrates, many of these assumptions are harshly and explicitly violated in practice, displaying a great deal of variability in the real practice of network organizations. To do justice to this variability, we propose to develop a more versatile and adjustable model that we call the 
multivalent negotiated network model (MNN). Our goal in developing MNN is not to discard and debunk the themes and assumptions just described, but to displace and enrich them. Therefore, in their place, we propose to consider a range of possibilities that could vary in terms of strength and nuance, as outlined in Table $4.1^{1}$

\section{TABLE 4}

Themes and Assumptions Characteristic of MNN

Themes

1. Cooperation

2. Voluntarism

3. Team Spirit

4. Decentralization

5. Empowerment

6. Transparency

1. Market orientation

2. Trust

3. "Stateless" firm

4. Adaptability

5. Informationalism

6. Internationalism
Antagonism

Opportunism

Individualism

Concentration of Power

Coercion

Secrecy

Background assumptions

Market manipulation

Deception

Political pressure

Gaming behavior

Strategic misinformation

Network protectionism

In line with these themes and assumptions, MNN portrays the network enterprise, in the most general case, as a collection of heterogeneous entities (firms, inter- and intrafirm bodies) with multiple links of varying strengths, which can be characterized anywhere from total cooperation, trust, and voluntarism to outright antagonism, deception, and coercion (see Figure 2). It follows from this characterization that the characteristic features of MNN and UCN fall on a continuum where the former would include the latter as a special case.

To illustrate the differences between UCN and MNN models, we check some of their central concepts against the information on Enron.

\section{Interfirm Cooperation and Trust}

Networks are evolving that possess characteristics similar in part to the Japanese keiretsu -an organizational collective based on cooperation and mutual shareholding among a group of manufacturers, suppliers, and trading and finance companies. (Miles \& Snow, 1992)

Cooperation among firms in different forms and capacities-asset, technology, expertise, information, etc.- -is the cornerstone of the network enterprise and what motivates a networking strategy in the first place. To be sure, any organization depends for its functioning on close cooperation with a huge number of partnerships, investment banks, creditors, analysts, auditors, and so on. There is, in other words, a certain degree of truth to the preceding assertion by Miles and Snow. But to conclude from this that cooperation is the only mode of interfirm relationship is rather simplistic. In fact, Miles and Snow (1992, p. 59) consider the possibility of noncooperative behavior, but underplay it with optimism: “Of course, the fact that network linkages are external does not guarantee that they will always be efficacious 
to each of the parties, but it does push the parties toward performance-based equity." This "push" does not seem to have prevailed in the case of Enron.

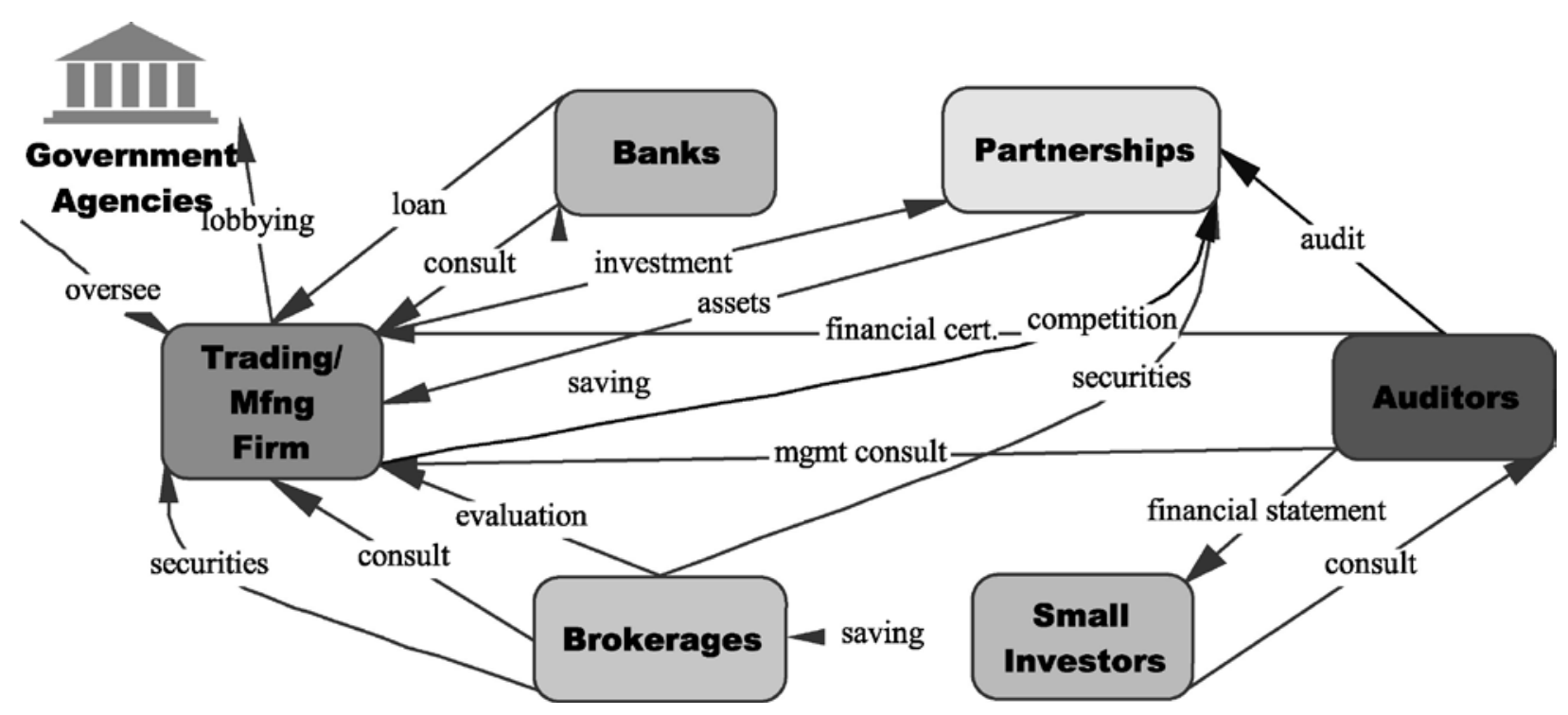

FIG. 2. A multivalent negotiated network.

There is compelling evidence of persistent noncooperative and even antagonistic links between Enron and its affiliates. A famous example of this antagonism is the case of JEDI, Enron's partnership with Calpers. Enron invested \$500 million in JEDI2 by first cashing out \$383 million from JEDI1, and used Chewco Investments as an “outsider” to pay \$383 million and take the place of Calpers (Powers' Report, 2002; Swartz \&Watkins, 2003). In other words, a large transaction took place on Calpers's money without its being aware of this. In light of this, the multiple relationships situation between Enron and Calpers could be depicted as one where cooperation constitutes only one link, and where other links can be characterized as manipulation, deception, game playing, and so on (see Figure 3). Similarly, the relationship of Enron and the auditing firm Arthur Anderson had multiple links, such as auditing, consulting, and management advice. As we showed earlier, Enron's links with investment banks and brokerage firms take a truly multivalent, nuanced, and dynamic character (see Figure 4). All of these could be characterized as "cooperation" at some level, but, as has become increasingly clear, they involve contradictory senses of cooperation based on a conflict of interest (Barboza \& Schwartz, 2002). Thus, any view that takes cooperation as the only mode will be pregnant with contradiction.

The preceding points lend support to our suspicion about the dominantly cooperative character of the links as the modus operandi of network organizations (cf. Van Alstyne, 1997), and to our claim about their multivalent, nuanced, and dynamic nature.

\section{Operational Transparency}

Even when a network's components are commonly owned, the essential structure of the organization is external—an exoskeleton of clearly specified, objectively structured contracts and buy-and-sell agreements that guide interactions rather than internal schedules, procedures, and routines. (Miles \& Snow, 1992) 


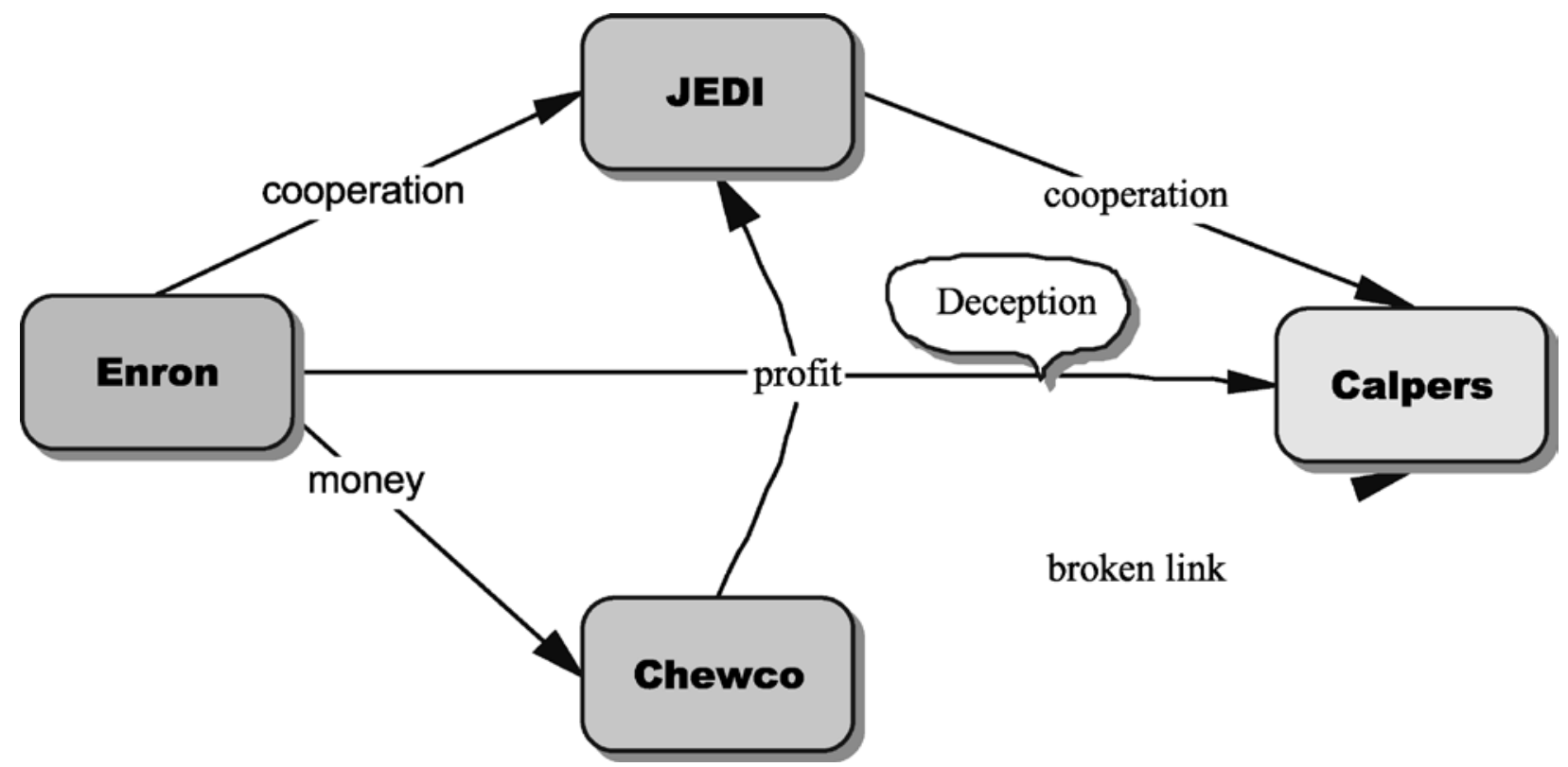

FIG. 3. Various links between Enron and its partners. 


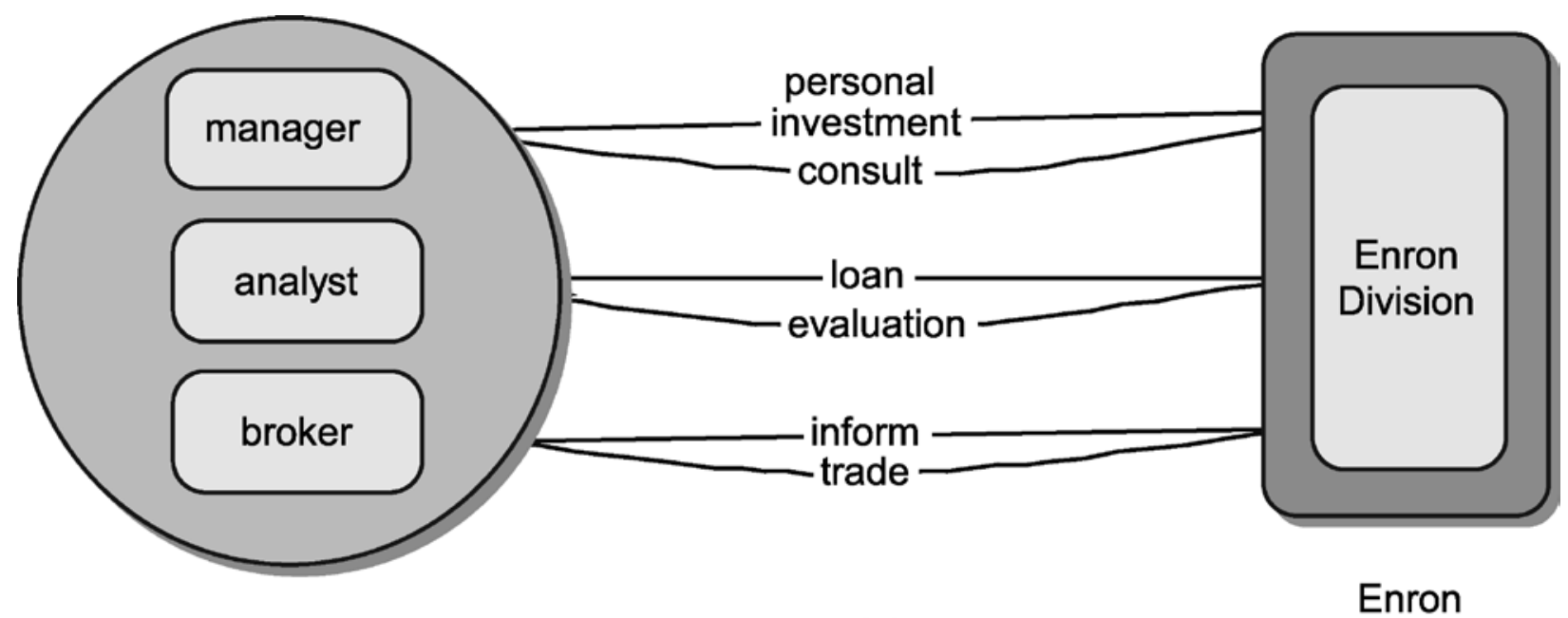

(a)
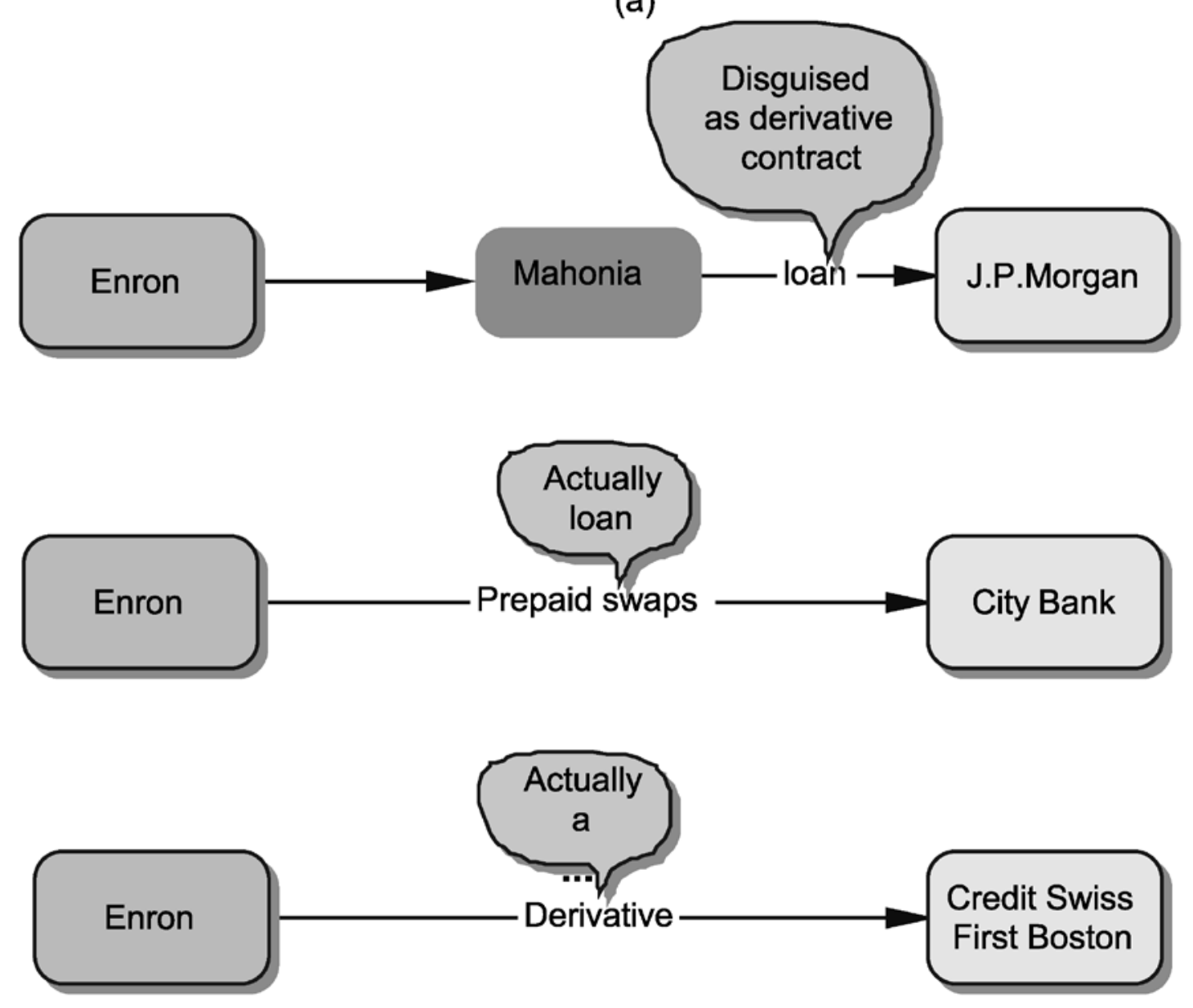

(b)

FIG. 4. Multivalent and dynamic relations between Enron and (a) brokerage firms and (b) banks.

Transparency of operations and practices is another aspect of the network organization highlighted in the cooperative model. Miles and Snow (1992, p. 57) consider transparency and 
voluntarism as "two unique characteristics of the network form." They assert that "the essential relationships among components are external (and thus highly visible to all parties)." Therefore, while considering the possibility that "attempts at personal gain may be made," these authors postulate that "the behavior will be much more transparent." They contrast this situation with that of older organizational forms where, for example, "cost data and/or performance measures may be manipulated by simply changing accounting conventions — such as the way in which overhead expenses are accumulated and assigned." Castells, similarly, posits that "On-line companies . . ., aware of the potential of the Internet, were the first to seize the opportunity to set themselves up entirely on the basis of computer networks that would open up the company's information and operations to both customers and suppliers” (2001, p. 68).

This assessment again is only partially true. The externality of the relations among firms can contribute to the transparency of transactions, but does not guarantee it. And nowhere is the lack of guarantee better demonstrated than the notorious accounting practices of organizations such as Enronpractices that, despite Miles and Snow's hypothesis, are much more open-ended and manipulable in the network context, and were indeed at the heart of NETWORK ORGANIZATIONS 163 Enron's networking strategy (Swartz \& Watkins, 2003). In partnerships, for example, Enron's common practice consisted of two rather orthogonal cycles. In one of them, Enron shifted failed businesses onto the partnership's accounts, and moved some assets, such as a water plant or a broadband unit, into the partnership. In the other, it borrowed loans, funded by investors such as J. P. Morgan, and booked them as earnings on assets. Accounting procedures and rules played a critical role in making these possible.

False accounting practices are not rare in American business (Coffee, 2002; Gosselin, 2002; Morgenson, 2002). What makes these undetectable is the so-called "impenetrability" of the numbers (Altman, 2002), which are sometimes made even more blurry and impenetrable in a network context. It was the blurry character of such transactions that allowed Enron to post in its balance sheets bank loans as "asset from price risk management" and their repayments as "liabilities from price risk management." Current accounting rules also add to this complexity (Mulford \& Comiskey, 2002). Coffee (2002) says: "Enron was ingenious about trying ways to exploit the ambiguities and the limitations of those rules. They in particular tried to treat the partnerships as independent entities, even though they might have liability for it.” This reveals that a certain degree of independence on the part of the affiliates was not only real, it was also desirable for Enron - a fact that should be considered in a realistic model of networking (see the sixth section of this article).

In view of these facts, it would be fair to conclude that the network form of enterprise not only fails to guarantee visibility and transparency, it creates new possibilities for hidden and covert, although “legal,” transactions.

\section{Decentralization, Teamworking, and Empowerment}

The organization itself has changed it organizational model, to adapt to the conditions of unpredictability ushered in by rapid economic and technological change. The main shift can be characterized as the shift from vertical bureaucracies to the horizontal corporation. . . . The "horizontal corporation" is a dynamic and strategically planned network of self-programmed, self-directed units based on decentralization, participation, and coordination. (Castells, 1996, p. 164) 
Network organizations are often described as lean or flat hierarchies, where management's major role is "to create learning-oriented partnerships within the firm and among network members," and leadership is viewed as "a shared responsibility among colleagues, not as a superior- subordinate relationship" (Miles \& Snow, 1995). The picture that is often portrayed is one of a "spherical structure" in which "resources are infinitely rotatable" and accessible from any point in the organization. Based on this picture, Miles and Snow advocate a "human investment philosophy," and mention a small computer graphics company as a prime example of the implementation of this philosophy. But they believe that the same approach would work in large companies, "though, of course, .. . [it] poses a considerable challenge." More than a challenge, however, this might be a dilemma arising from the dual aspects of decentralization-namely, the balance between participation and flexibility, on the one hand, and coordination and stability, on the other. Different authors have discussed this dilemma. Murray and Wilmott (1997, p. 169), for instance, discuss the possibility that "the establishment of quasi-autonumous profit centers . . . may have the unintended effect of fragmenting and unbalancing established structures.” Foss (2001) has invoked the problem of "selective intervention" to discuss the organizational and psychological barriers that lie on the road to full-fledged decentralization. Sassen (1998) argues that decentralization has also brought about an unprecedented concentration of activity and power in certain regions of the world, and Sennett (1998) articulates the broader impacts of the flexible mode of work in new capitalism on human life and personal characters. Castells (1996, p. 166) also mentions this difficulty, but nevertheless he portrays the "horizontal corporation” as "a dynamic and strategically planned network of self-programmed, selfdirected units based on decentralization, participation, and coordination.” The picture in Enron seems to have been quite different.

Enron is often described as a highly decentralized corporation, with its executives pushing decentralization to an extreme, encouraging business units to compete rather than cooperate (Beritano, 2002). But this policy had its flip side - that is, the segmentation of the organization into noncooperative units set up as "silos" or "islands" (Swartz \&Watkins, 2003, p. 59). An expert once described Enron as a "compartmentalized structure like the CIA," where each department does its own job without knowledge of others (PBS News Hour February 8, 2002). Furthermore, as former Enron employees have revealed, coercion was a daily fact of life at Enron (Cruver, 2002).

In sum, this means that compartmentalization, coercion, and concentration of power and not just decentralization, team spirit, and empowerment characterize network organizations.

\section{Market Competition, Deregulation and Globalization}

Financial markets, by and large, are outside anyone's control. They have become a sort of automaton, with sudden movements that do not follow a strict economic logic, but a logic of chaotic complexity, resulting from the interaction of millions of decisions reacting in real time, in a global span, to information turbulences from various origins-including economic news concerning profits and earnings. Or their anticipation. Or the reversal of what was expected. (Castells, 2001, p. 87)

A key underlying assumption in theories of the new economy is the shift from mass production to flexible production based on competitiveness and productivity (Castells, 1996, pp. 154-156). The resilient presence of small and medium firms, as "agents of innovation and sources of job creation," is seen as giving rise to a market that is pretty much out of anyone's control (Castells, 2001, 88). This 
account of the new market, while partially true, invests too much hope and optimism in the efficacy of the Darwinian mechanisms of the market. The inadequacy of such mechanisms found a vigorous expression in Enron's activities in the energy and bandwidth markets (Krugman, 2002; Oppel, 2002). While the legal aspects of such activities are still debated, their implications for the present topic are rather obviousnamely, despite the optimism about the autonomy of the market, instances such as these reveal that the prevailing complexities have created ample opportunities for intrusion, collusion, and meddling in the market.

Closely related themes to market competition are deregulation and privatization. Often considered as effective mechanisms for enhancing productivity and competitiveness in the global market, these themes find political expression in current trends to demote the role of the state in economic decisionmaking. Castells shares the conviction that deregulation plays an important role in the current economy, but differs from it in giving the state a decisive economic role at the same time (1996, p. 90). He justifies his position by the interdependence of international markets, which necessitates the close engagement of governments as strategic planners of national economies. On the other hand, he argues that the power of the nation-state is dispersed among many other organizations that undermine the central role of the government (Castells, 2000). Castells's main hypothesis in this respect is that, "as the process of globalization progresses, organizational forms evolve from multinational enterprises to international networks" (p. 192). He argues that networks are asymmetrical in regards to the international distribution of wealth and power, but suggests that no single element can impose its diktat because of the "logic of the network” (pp. 192-193). Unfortunately, Castells does not explain how this logic overcomes (or even ameliorates) asymmetry and prevents imposition. In fact, the case of Enron shows that this logic does not necessarily prevail.

It is now public knowledge that, despite a strong advocacy of deregulation, Enron had a strong web of political influence in all branches of the government (Institute for Public Studies, 2002). The main objective of this lobbying activity was the deregulation of the energy market, which was often used to raise margins and prices rather than raising competition and openness. On the global scene, there is solid documentation of the unilateral and impositional character of many projects carried out by Enron, their adverse social and political impacts, and the role of US and local governments as well as international agencies in implementing them (Wysham, 2002). It is suggested further that many of these adversities were simply ignored until their consequences began to be manifested in the American scene. All of these indicate not only the shakiness of the notion of a "stateless firm" invoked by organization theorists such as Miles and Snow, but also the impotency of Castells's networking logic in preventing power asymmetries in the global marketplace.

\section{Informationalism}

The new economy, spearheaded by e-business, is not an on-line economy, but an economy powered by information technology, dependent on self-programmable labor, and organized around computer networks. (Castells, 2001, p. 99)

Information and knowledge, according to many accounts, is the hallmark of the current economy (Castells, 1996, 2001), and ICT is featured as having more than one role in today's network organization (Fulk \& DeSanctis, 1998). The interesting question to ask is, What role does information technology play in the development of a network organization? 
Expert opinions vary on this question. During Enron's heyday, almost everyone praised Enron for its innovative approach to IT application (Durgin, 1994; PR Newswire, 1997; Dow Jones News Service, 1998; Kranhold, 1999; Wilson, 1999; Kirkpatrick, 2000; Maselli, 2001; Poruban, 2001). But opinions tend to diverge in the aftermath of Enron's collapse. Some IT experts point out the issues of incompatibility among different IT systems and applications, while others emphasize usability and inconsistency —as one IT specialist put it, "Enron IT was as cutting edge as it was byzantine ... They ran a $\$ 100$ billion company on Access and Excel” (Beritano, 2002).

The common thread in these reports is that Enron's management had not planned its ICT, and this resulted in the depletion of resources, the interruption of information processes, and the disorganization of data ("islands of data"; Baritano 2002). ICT indeed contributed to Enron operations in terms of speed, scope, scale, and even pubic relations (Ekbia, 2004), but it did not have a decisive impact on the company's direction.2 As Murray and Wilmott (1997, p. 167) have argued, "It is one thing to acknowledge the presence of ICT. It is quite another to argue that they are radically transforming the structure of organizations and societies.” The failure of Enron confirms once again the lesson that technology by itself does not drive organizational change (Kling\&Lamb, 2000; Symon, 2000).

Furthermore, we argue that network organizations do not, in principle, depend upon computer networks or the Internet. Take, for example, Hollywood production NETWORK ORGANIZATIONS 165 companies or general contractors who remodel or renovate homes. Due to their project-oriented character, these enterprises have most of the characteristics of the new network enterprise, but are in no serious way dependent upon ICT. Castells correctly points out that the network model is a traditional form of organization with a long history in different industries and different parts of the world. However, he suggests, what is new about the emerging network enterprise is its informational character that closely binds it to the advances in ICT. We argue, to the contrary, that those network enterprises that extensively employ such technologies do not solely depend on the Internet for expediting communication. Rather, they depend upon proprietary networks and telephone networks as well as the Internet for this purpose. In short, the dependence of network enterprises, even in their recent emerging forms, on information technology and the Internet in particular is far from established.

\section{DISCUSSION}

What emerges from the preceding analysis is a picture of the network organization that is much more complex and variegated than existing analytical models allow. We would like, in this section, to outline the general features of the proposed MNN model that, we believe, allows for greater analytical robustness. This list of features is by no means exhaustive; it is meant to highlight those aspects of the network enterprise that are often underplayed in the existing models.

Heterogeneity. The players in a network organization usually have different characteristics and roles. They might vary from an internal operational division of an organization (e.g., sales, technology, human resources) to different types of interorganizational alliances and partnerships (branding, franchising, joint ventures, subcontracting, interlocking directorates, etc.) with varying relationships among them (investment, auditing, analysis, stock trading, etc.). Each of these, in turn, might allocate different resources (equipment, money, technology, information, etc.) to the network with its own set of links and flows. The model should account for this heterogeneity of actors and relationships.

Autonomy and asymmetry. A network organization is a collection of various intra- and extraorganizational entities with their respective goals, resources and strategies. The character of the network 
depends on the strength and character of the links among these entities. A model of a network organization, therefore, should account for these entities both as elements of the network and as independent players with their idiosyncratic roles. In particular, the model should be able to account for the real, although murky and elastic, boundaries between the entities and possible asymmetries in their relations.

Nuance and multivalence. The relationships between any two actors in a network organization might be multiple, variegated, and unstable. They might vary from complete cooperation to relative independence or even antagonism. Each of these relations may, in turn, come in different degrees of strength and nuance. The model should account for these multivalent and nuanced links within network organizations. Dynamism. The overall structure of a network organization or parts thereof may undergo continuous and rapid change. The extremely competitive nature of the current economy, the shortening of business cycles, and the relentless change in technology are the outstanding features of the environment within which network organizations are operating. This, in turn, calls for the capability of timely response to such change on the part of the network. As many analysts have mentioned, this dynamic environment is largely responsible for the emergence and burgeoning of the network form of organization in recent years. A model should adequately account for this dynamic aspect of network organizations.

Nondeterminism. The global scope of the current economy is another outstanding feature that distinguishes it from previous periods. Information and communication technology is often identified as the technical precursor and a necessary vehicle for the implementation of recent forms of network organization. As a matter of fact, network forms of social organization, as Castells (2000) points out, predate ICT. The Internet and other ICT media make possible the transfer and exchange of various data and information across the globe in very little time. The role of ICT should be understood as a dual one in the emerging network organizations. On the one hand, it empowers organizations by allowing them to perform more efficiently, more quickly, and more knowledgeably. On the other, it has the potential of creating information overload, of employee alienation, and of misleading business leaders and managers into complacency and a false sense of control (Symon, 2000). To avoid the biases of technological determinism (Kling, 1997), a realistic model of network organization should take these dual aspects of technology into account.

Contingency. The network model is different in many respects from other forms of organization, but it inevitably shares the property of being contingent (Sonnentag, 2000). There is, in otherwords, no hidden magic in this model that would guarantee the ultimate success of its implementation. Network organizations face new challenges that must be constantly met. As such, they are as likely to fail as any other business. Arealistic model should be unbiased in the sense of predicting and accounting for both successes and failures. Such a model would involve, as a special case, the fully cooperative model of network organizations that is usually discussed in the literature.

In sum, we believe that the issues discussed here, while not ignored in prior works on network organization, deserve more attention. In particular, the heterogeneity of players and the nuanced and multivalent character of the links among them merit close attention. These observations are borne out by some of the prominent examples of network organization. Recent accounts of Cisco's acquisition policy, for instance, confirm the main premise of our analysis about the nuanced and multivalent character of the links in network organizations, even in the most celebrated cases. In their detailed analysis of the implementation of this policy before and after acquisition, Mayer and Kenney (2002) emphasize the importance not only of due diligence in the acquisition process, but also of the many dimensions of sociocultural similarity between the acquired firms (usually high-technology startups) and the acquiring 
firm (Cisco in this case). In a recent acquisition reported in the media (namely, that of Linksys), Cisco has adopted a novel strategy that gives a lot of autonomy to the acquired firm in order to inhibit, among other things, the "meddling" of Cisco employees in the affairs of the subsidiary (Wall Street Journal, 2003). Such examples show that the significance of conflicts and mismatches goes way beyond day-to-day trivialities to attain a strategic level. Companies like Cisco implement effective networks, not because they neglect or streamline these aspects, but mainly because they incorporate them in their strategic planning. The network model does not automatically bring about, as Castells seems to suggest, this “chemistry of innovation” (2001, p. 71). Likewise, companies like Enron structurally fail, mainly because of their meddling in the affairs of other network participants (e.g., partners, small investors, auditing firms) and the meddling of some other participants (e.g., large banks, analysts, etc.) in Enron affairs. This is not to say that there are not other differences between Enron and Cisco-for example, in terms of organizational culture, strategy, ethics, industry, and so on. It is to say that the story of Enron is, among other things, a structural failure under the tensions generated by internal and external antagonism, mistrust, secrecy, and so on.

\section{CONCLUSION}

In an interesting coincidence, a recent special issue of The Academy of Management Executive (2003) on "building effective networks" features both Miles and Snow (Ketchen, 2003) and SherronWatkins (Pearce, 2003), former Enron vice-president. What is interesting about these reports is the sharp contrast of perspectives represented in them. Although, in harmony with their previous views, Miles and Snow reiterate "the use of 'dynamic networks' to expand reach and flexibility of the firm," Watkins is concerned about the widespread lack of trust in business leaders (which is at its lowest point in decades). It is this difference in perspectives that the present article tries to highlight and accommodate.

Sociologists such as Castells have made network organizations the centerpiece of their theorizing about network societies. Castells's emphasis on network societies leads us to feel comfortable with networked organizations and multinational firms. While he points out conflicts (in markets, for instance), his overall portrayal of these organizations is one of "well-behaved" entities. From what we have learned about Enron, it is amazing to see simultaneously how much Enron fits Castells's characterization of the network enterprise "as an intermediary that collects a fee for its ability to process information" and how much it fails to show the other attributes suggested by Castells and taken for granted in the popular and academic literature. Common among these are assumptions of cooperation between all nodes, together with normal forms of "due diligence" and honesty when participants are in a relationship such as auditing. Furthermore, there is usually a narrow focus on the "production organization," whereas the functioning network may also include partners such as venture capitalists, investment bankers, and even competitors.

The reality of network organizations is much more complex than the typical conceptions of network organizations. While the network form is an advance over post-bureaucratic organizations, it is more convoluted, complicated, and pregnant with paradoxes. It might be flat, flexible, and team-oriented, but the flip side of these, as Sennett (1998, p. 138) has argued, is uncertainty, the absence of deeply rooted trust and commitment, and the superficiality of teamwork. "Howcan mutual loyalties and commitments be sustained," Sennett wonders, "in institutions which are constantly breaking apart or continually being redesigned?” (p. 10). By the same token, the new economy might thrive in an unregulated and decentralized environment but, as Sassen $(1998,2001)$ has shown, it has also brought about expanded 
central control and a concentration of power in certain metropolitan areas of the world. It is questions and paradoxes like these that we have tried to address here and to capture in the proposed model.

This broadened perspective leads to a much more realistic picture of the network enterprise. The accommodation of the contradictory aspects detailed in Table 4 in the same model is the major advantage of MNN, especially in its application to the information sectors. This analysis does not apply only or even primarily to organizational crime. It may be especially applicable to new organizations or to firms that are operating in new and ill-understood industries or with new or poorly defined business models and practices. Whether we consider cases such as Amazon, Cisco, Walmart, and big pharmaceutical companies, or take large-scale corporate scandals and failures such as Dynergy, Enron, Tyco, Worldcom, and so on, the multivalent negotiated model (MNN) suggested here equally applies. In the MNN view, Cisco and Enron are different, not because one instantiates an ideal network organization and the other does not, but because they fall on opposite ends of the spectrum on a number of important dimensions highlighted in the MNN model. The managerial implications of this view are also notable. As Porter (1998, p. 87) has concluded from his study of "clusters," executives must extend their thinking beyond what goes on inside their own organizations; "strategy must also address what goes on outside." Our analysis leads to a similar conclusion. In addition, our model suggests, managers should pay specific attention to the various dimensions highlighted in MNN, making sure that their organizations fall on the appropriate point on the continuum. Only then can an organization reap the fruits of having a network structure.

\section{NOTES}

1. Some of the proposed terms need to be qualified. Generally speaking, all of the mentioned "themes" are relative to the network-that is, their operational scope is the boundary that separates the network from the outside world. Themes such as "secrecy" and "self-interest" should, therefore, be understood within this boundary, not in the relationship between the network and its environment.

2. In this regard, a former Enron officer wrote to the first author and explained how Enron used IT to "intimidate potential competitors into believing that the barriers to emulating Enron's very real (early) successes were higher than truly were.”

\section{REFERENCES}

Abell, P., and Reyniers, D. 2000. On the Failure of Social Theory. British Journal of Sociology 51(4):739-750.

Altman, D. 2002. Enron had more than one way to disguise rapid rise in debt. New York Times, February 17.

Baker, W. 1992. The network organization in theory and practice. In Networks \& Organizations, eds. N. Nohria and R. Eccles, pp. 142- 162. Basingstoke: Macmillan.

Banerjee, N., Barboza, D., andWarren, A. 2002. At Enron, lavish excess often came before success. New York Times, February 26.

Barboza, D., and Schwartz, J. 2002. The finance wizard behind Enron’s deals. New York Times, February 6.

Bell, D. 1973. The coming of postindustrial society: A venture in social forecasting. New York: Basic Books. 
Beritano, S. 2002. Enron IT: A tale of excess and chaos. CIO. http://www.cio.com/executive/edit/030502enron.html (accessed April 2003).

Bilodeau, O. 2002. In eye of Enron storm, a partnership is rocked. Legal Times, February 21.

Bovasso, G. 1992. A structural analysis of the formation of a network organization. Group \& Organization Management 17(1):86-106.

Bryce, R. 2001. Fueling bandwidth trading: How energy companies plan to change telecom. Interactive Week 8(31):20-23.

Burns, T., and Stalker, G. 1961. The management of innovation. London: Tavistock.

Camuffo, A., Romano, P., and Vinelli, A. 2001. Back to the future: Benetton transforms its global network. MIT Sloan Management Review 43(1):46-52.

Castells, M. 1996. The rise of the network society. Malden, MA: Blackwell.

Castells, M. 2000. Materials for an explanatory theory of the network society. British Journal of Sociology 51(1):5-24.

Castells, M. 2001. The Internet galaxy: Reflections on the Internet, business, and society. Oxford, UK: Oxford University Press.

Chaffin, J. 2002. Enron complaint cites “sham” Merrill deal. Financial Times, October 2.

Ching, C., Holsapple, C. W., and Whinston, A. B. 1996. Toward IT support for coordination in network organizations. Information \& Management 30:179-199.

Coffee, J. 2002. Accounting for bad accounting. An interview. http://www.essential.org/monitor/enroncoffee.html (accessed February 2003).

Crabtree, J. 2002. The cult of Castells. Prospect February:50-54.

Creswell, J. 2002. Banks on the hot seat. Fortune Magazine 146(4):79- 82.

Cruver, B. 2002. The anatomy of greed: The unshredded truth from an Enron insider. New York: Carroll \& Graf.

DeSanctics, G., and Fulk, J. 1999. Shaping organizational form: Communication, connection, and community. Newburg Park, CA: Sage.

Dow Jones News Service. 1998. Power Shock-3: Enron known as sophisticated risk manager. July 9.

Durgin, H. 1994. Natural gas traders inch into computer age. Houston Chronicle, July 31.

Eades, J. 2000. The Information Age book review. Journal of the Royal Anthropological Institute 6(2):340-341.

Eisenhardt, K. M. 1989. Building theories from case study research. Academy of Management Review 14(4):532-550.

Ekbia, H. R. 2004. How IT mediates organizations: Enron and the California energy crisis. Journal of Digital Information 5(4). http://jodi.ecs.soton.ac.uk/Articles/v05/i04/Ekbia/.

Foss, N. J. 2001. Selective intervention and internal hybrids: Interpreting and learning from the rise and decline of the Oticon spaghetti organization. DRUID Working Paper No. 01-16. http://econpapers. repec.org/paper/aalabbswp/01=16. htm (accessed June 2003).

Fulk, J. 2001. Global network organizations: Emergence and future prospects. Human Relations 54(1):91-99.

Gosselin, Peter G. 2002. Enron a Rerun of History. L.A. Times, February 22.

Grandori, A., and Soda, G. 1995. Inter-firm networks: Antecedents, mechanisms and forms. Organization Studies 16(2):183-214.

Greider, W. 2002. The Enron nine. The Nation, May 13. 
Hanssen-Bauer, J., and Snow, C. 1996. Responding to hypercompetition: The structure and processes of a regional learning network organization. Organization Science 7(4):413-427.

Institute for Policy Studies. 2002. Enron's pawns: How public institutions bankrolled Enron's globalization game. March 22. http:// www.seen.org/PDFs/pawns.PDF (accessed September 23).

Ketchen, D. J., Jr. 2003. An interview with Raymond E. Miles and Charles C. Snow. The Academy of Management Executive 17(4):97- 104.

Kirkpatrick, D. 2000. Enron takes its pipeline to the net. Fortune 141(2):127-131.

Kling, R., ed. 1997. Computerization and controversy. San Diego, CA: Academic Press.

Kling, R. In press. The Internet Galaxy book review. Unpublished manuscript.

Kling, R., and Lamb, R. 2000. IT and organizational change in digital economics: A socio-technical approach. In Understanding the digital economy-Data, tools and research, ed. B. K. E. Brynjolfsson. pp. 295-324. Cambridge, MA: MIT Press.

Kraak, A. 2000. Debating Castells and Carnoy on the network society. The Gauteng Seminars. http://www.anc.org.za/ancdocs/ pubs/umrabulo/umrabulo9c.html\#f1 (accessed in January 2004).

Kranhold, K. 1999. Enron to unveil pact involving RealNetworks. Wall Street Journal, January 21.

Krugman, P. 2002. Everyone is outraged. New York Times, July 2.

Maselli, J. 2001. Information: The most valuable asset. Information Week 852:32-33.

Mayer, D., and Kenney, M. F. 2002. Economic action does not take place in a vacuum: Understanding Cisco's acquisition and development strategy. BRIE Working Paper 148.

Miles, C. C., and Snow, R. E. 1992. Causes of failure in network organizations. California Management Review 34(4):53-67.

Miles, C. C., and Snow, R. E. 1995. The new network firm: A spherical structure built on a human investment philosophy. Organizational Dynamics 23(4):5-20.

Miles, C. C., Snow, R. E., and Coleman, H. J., Jr. 1992. Managing 21st century network organizations. Organizational Dynamics 20(3):5- 21.

Morgensen, G. 2002. Information sooner, Yes, but make it better, too. New York Times, May 5.

Mulford, C. W., and Comiskey, E. E. 2002. The financial numbers game: Detecting creative accounting practices. New York: John Wiley.

Murray, F., andWilmott, H. 1997. Putting information technology in its place: Towards flexible integration in network age? In Information technology and organization: Strategies, networks, and integration, ed. B. P. Bloomfield, pp. 160-180. Oxford, UK: Oxford University Press.

Nohria, N., and Eccles, R., eds. 1992. Networks and organizations. Boston: Harvard Business Press.

Oppel, R. A., Jr. 2002.Wall Street analysts faulted on Enron. New York Times, February 28. PBS News Hours, February 8, 2002.

Pearce, J. L. 2003. Former Enron vice president Sherron Watkins on the Enron collapse. Academy of Management Executive 17(4):119- 125.

Polodny, J. M., and Page, K. L. 1998. Network forms of organization. Annual Review of Sociology 24:5776.

Porter, M. 1998. Clusters and the new economics of competition. Harvard Business Review NovemberDecember:77-90.

Poruban, Steven. 2001. Enron's Lay sees more e-commerce changes for industry. Oil and Gas Journal 99(16):32-33. 
Powell, W. W. 1990. Neither market nor hierarchy: Network forms of organization. In Research in organizational behavior, eds. L. L. Cummints and Barry M. Staw, vol. 12, pp. 295-336. Greenwich, CT: JAI Press.

Powell, W. W. 2000. The capitalist firm in the 21st century: Emerging patterns. In The twenty-first century firm, ed. P. DiMaggio. pp. 33-68. Princeton, NJ: Princeton University Press.

PR Newswire. 1997. Enron announces first metering systems using twoway wireless communications and a satellite-enabled network for all electricity consumers. December 15.

Powers' Report. 2002. Report of investigation by the special investigative committee of the board of directors of Enron Corp. http://news. findlaw.com/hdocs/docs/enron/sicreport/ (accessed July 2003).

Ragatz, G. L., Handfield, R. B., and Petersen, K. J. 2002. Benefits associated with supplier integration into new product development under conditions of technology uncertainty. Journal of Business Research 55:389-400.

Rubenstein, D. 2001. Oil change: At Enron, a decade of transformation. Corporate Legal Times 11(119):1-4.

Sassen, S. 1998. Globalization and its discontents. New York: New Press.

Sassen, S. 2001. The global city, 2nd ed. Princeton, NJ: Princeton University Press.

Sennett, R. 1998. The corrosion of character: The personal consequences of work in the new capitalism. New York: W.W. Norton.

Share, J. 1999. Enron executive hopeful over prospects in Africa, Asia. Pipeline \& Gas Journal 226(8):20-24.

Sherman, S. 2002. Enron: Uncovering the uncovered story. Columbia Journalism Review March/April. http://www.cjr.org/year/ 02/2/shreman.asp (accessed August 2003).

Sonnentag, S. 2000.Working in a network context-what are we talking about? Comment on Symon. Journal of Occupational and Organizational Psychology 73(4):415-418.

Staider, F. 1998. The network paradigm: Social formations in the age of information. The Information Society 14(4):301-309.

Swartz, M., and Watkins, S. 2003. Power failure: The inside story of the collapse of Enron. New York: Doubleday.

Symon, G. 2000. Information and communication technologies and network organization: A critical analysis. Journal of Occupational and Organizational Psychology 73(4):398-414.

Van Alstyne, M. 1997. The state of network organization: A survey in three frameworks. Journal of Organizational Computing 7(3):83- 151.

Wall Street Journal. 2003. While some companies whisper, others crow. June 9.

Wayne, L. 2002. Congress to investigate Wall St.’s ties with Enron. New York Times, February 19.

Wilson, Carol. 1999. Building a better backbone-And business plan. Interactive Week 6(36):39-42.

Wysham, D. 2002. Enron's empire: How government and international agencies used taxpayers' money to bankroll the energy giant's international investments. http://www.corpwatch.org/issues/ PID.jsp?articleid = 2279 (accessed August 2003). 